\title{
Nitrogen oxides in the troposphere - What have we learned from satellite measurements?
}

\author{
A. Richter ${ }^{\mathrm{a}}$ \\ Institute of Environmental Physics, University of Bremen, 28359 Bremen, Germany
}

\begin{abstract}
Nitrogen oxides are key species in the troposphere where they are linked to ozone formation and acid rain. The sources of nitrogen oxides are anthropogenic to large extend, mainly through combustion of fossil fuels. Satellite observations of $\mathrm{NO}_{2}$ provide global measurements of nitrogen oxides since summer 1995, and these data have been applied for many studies on the emission sources and strengths, the chemistry and the transport of $\mathrm{NO}_{x}$. In this paper, an overview will be given on satellite measurements of $\mathrm{NO}_{2}$, some examples of typical applications and an outlook on future prospects.
\end{abstract}

\section{$1 \mathrm{NOx}$ in the troposphere}

Nitrogen oxides play several important roles in the atmosphere. In the stratosphere, they act as catalysts in ozone destruction reducing ozone levels and at the same time form reservoir substances with the halogen oxides thereby reducing their ozone depletion potential.

In the troposphere, photolysis of $\mathrm{NO}_{2}$ is the only known route for ozone formation. As ozone is also rapidly destroyed by reaction with $\mathrm{NO}$, nitrogen oxides $\left(\mathrm{NO}_{x}=\mathrm{NO}+\mathrm{NO}_{2}\right)$ and ozone are often in photochemical equilibrium in the troposphere. In the presence of $\mathrm{HO}_{2}$ or peroxy radicals $\left(\mathrm{RO}_{2}\right), \mathrm{NO}_{2}$ is reformed without destruction of an ozone molecule leading to accumulating of $\mathrm{O}_{3}$. Thereby, high levels of $\mathrm{NO}_{x}$ together with volatile organic compounds and sufficient illumination lead to photochemical smog. Through reaction with ozone, $\mathrm{NO}_{2}$ forms the nitrate radical which is rapidly photolysed during daytime but at night takes over the role of $\mathrm{OH}$ as the most reactive radical in the troposphere.

$\mathrm{NO}_{2}$ can also react with $\mathrm{OH}$ to form $\mathrm{HNO}_{3}$ which is easily taken up by droplets and aerosols. Nitrate aerosols are also formed via formation of $\mathrm{N}_{2} \mathrm{O}_{5}$ from the reaction of $\mathrm{NO}_{3}$ and $\mathrm{NO}_{2}$ and subsequent hydrolysis on surfaces and droplets. Through this pathway, $\mathrm{NO}_{x}$ contributes to acidification of aerosols and cloud droplets which eventually impacts on ecosystems (acid rain). As emissions of $\mathrm{SO}_{2}$ have been dramatically reduced over the past decades, the relative importance of $\mathrm{HNO}_{3}$ has increased in most industrialised countries.

Nitrogen oxides are also relevant for radiative forcing. Locally, high levels of $\mathrm{NO}_{2}$ can be reached and direct absorption of sunlight becomes significant [1]. More indirectly, $\mathrm{NO}_{x}$ levels determine the amount of ozone formed in the troposphere, and $\mathrm{O}_{3}$ is an important climate gas. At large concentrations, $\mathrm{NO}_{x}$ also impacts on $\mathrm{OH}$ levels which in turn determines the life time of many greenhouse gases. A simplified overview on the chemistry of $\mathrm{NO}_{x}$ in the troposphere is given in figure 1.

The sources of $\mathrm{NO}_{x}$ in the troposphere are both natural and anthropogenic. Microbial processes in soils, oxidation of biogenic $\mathrm{NH}_{3}$, wild fires and lightning are natural sources of $\mathrm{NO}_{x}$. Today, fossil fuel combustion is the largest source of $\mathrm{NO}_{x}$ and together with the emissions from biomass burning, anthropogenic activities dominate the $\mathrm{NO}_{x}$ budget. The uncertainty of

\footnotetext{
a e-mail: andreas.richter@iup.physik.uni-bremen.de
} 


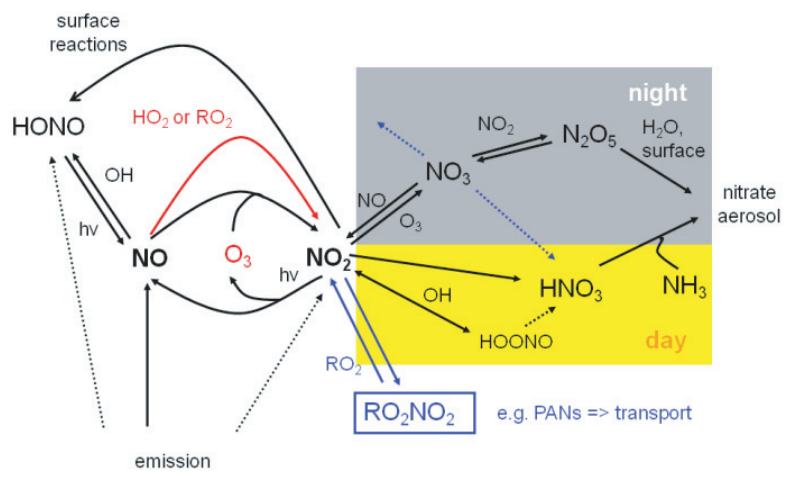

Fig. 1. Simplified sketch of the chemistry of $\mathrm{NO}_{x}$ in the troposphere. Adapted from M. Jenkin.

current emission estimates is surprisingly large with $30 \%$ for the anthropogenic contribution and more than a factor of 2 for lightning.

\section{Satellite measurements of tropospheric $\mathrm{NO}_{2}$}

Satellite measurements of $\mathrm{NO}_{2}$ are based on application of optical absorption spectroscopy to scattered sunlight. The $\mathrm{NO}_{2}$ molecule has strong and structured absorption bands in the UV and visible spectral range which makes it an ideal target gas for retrievals using the Differential Optical Absorption Spectroscopy (DOAS, [2-4]). Photons coming from the sun penetrate the atmosphere and are either reflected on the surface or scattered on air molecules, aerosols or clouds. DOAS analysis of the scattered light observed from nadir viewing satellite instrumentation yields the total $\mathrm{NO}_{2}$ absorption along the light path through the atmosphere. To convert this quantity to the tropospheric $\mathrm{NO}_{2}$ column, the stratospheric component has to be removed and the change in measurement sensitivity with altitude has to be taken into account. Details on the analysis of satellite measurements can be found in [5-9].

The first instrument to observe tropospheric $\mathrm{NO}_{2}$ from space was the Global Ozone Monitoring Experiment (GOME, [10]). It provided global measurements at a ground pixel size of $320 \times 40 \mathrm{~km}^{2}$ from July 1995 until June 2003 and has only limited coverage since then. Improved spatial resolution of $60 \times 30 \mathrm{~km}^{2}$ is provided by the Scanning Imaging Spectrometer for Atmospheric Chartography (SCIAMACHY) which was launched into orbit on ENVISAT in March 2002 [11]. Even more spatial details are available from the Ozone Monitoring Instrument (OMI) which is operational since August 2004 and has ground pixels of $24 \times 13 \mathrm{~km}^{2}$ to $150 \times$ $13 \mathrm{~km}^{2}$ with full global coverage every day [12]. Long-term continuation of the tropospheric $\mathrm{NO}_{2}$ time series is secured through GOME-2, a series of three instruments flown on the MetOp platforms of which the first is providing data since March 2007 [13]. GOME-2 has a spatial resolution of $80 \times 40 \mathrm{~km}^{2}$ and nearly daily global coverage.

The main advantage of satellite measurements is the fact that they provide global coverage and a data set which is relatively uniform in space and time. This makes them ideal tools for model validation, analysis of spatial distributions, temporal changes and global monitoring. However, there also are several limitations which have to be considered when using products of the current generation of satellite instruments.

A fundamental problem of satellite measurements of $\mathrm{NO}_{2}$ is the lack of vertical resolution. The quantity derived from the spectra is the integrated tropospheric column averaged over the ground pixel. This is a very different quantity from the mixing ratios at a given location in a certain altitude which is determined by standard in-situ measurements. This implies a difficulty for validation of the satellite measurements as the $\mathrm{NO}_{2}$ distribution in the troposphere is very inhomogeneous and a large number of in-situ measurements would be needed for proper comparison. Also, the satellite measurements can not directly distinguish between $\mathrm{NO}_{2}$ released from pollution at the surface and the emission of lightning $\mathrm{NO}_{x}$ at the top of a cloud. 


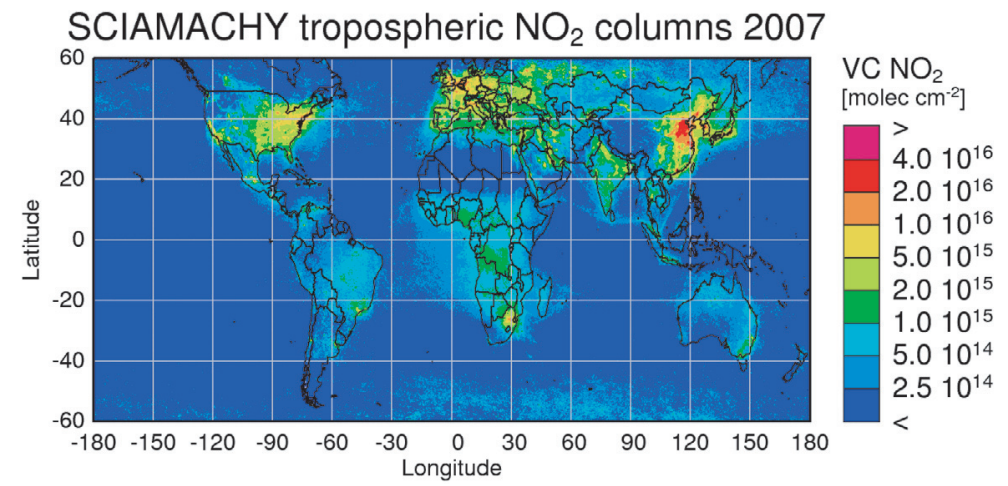

Fig. 2. Nearly global map of tropospheric $\mathrm{NO}_{2}$ columns from all cloud cleared measurements (cloud fraction less than 20\%) of SCIAMACHY for the year 2007.

As all remote sensing measurements, tropospheric $\mathrm{NO}_{2}$ retrieval from satellite measurements is an indirect observation and uses a priori assumptions. The most important ones are the shape of the vertical $\mathrm{NO}_{2}$ distribution, the surface reflectivity and the aerosol loading. Uncertainties in these assumptions have a large impact on the $\mathrm{NO}_{2}$ columns retrieved. The largest effect on the observations is from clouds which depending on their extension shield parts or the entire lower atmosphere from the satellite view.

More technical limitations arise from the limited spatial resolution of current instruments which leads to varying degrees of horizontal averaging and the fact that at this time, all instruments are in sun-synchronous polar orbits. The latter implies that the measurements at a given point are always taken at the same local time (morning for GOME, SCIAMACHY and GOME-2, noon for OMI) and therefore no diurnal profile can be obtained. A first comparison of data taken from OMI and SCIAMACHY indicates systematic differences between the two data sets which can be linked to diurnal changes in emissions, photochemistry and viewing conditions [14].

\section{Results and applications}

\subsection{The global $\mathrm{NO}_{2}$ distribution}

When GOME data became available in 1995, the first global maps of tropospheric $\mathrm{NO}_{2}$ based on actual measurements could be created. Up to that point, only atmospheric models could provide this type of information, and very little independent data was available for validation of the models and the inputs used by them. In figure 2, an example of such satellite maps is shown using all cloud cleared measurements of the SCIAMACHY instrument from 2007. A number of interesting conclusions can be drawn from these maps.

First of all, it is clear that the highest columns of $\mathrm{NO}_{2}$ are observed over the industrialised parts of the world, mainly the US, Europe, Asia and South Africa. In 2007, $\mathrm{NO}_{2}$ above China is by far the most prominent feature but that was not the case in the first maps [8]. This will be discussed in more detail in section 3.3.2. The high values over industrialised regions indicate that there, anthropogenic emissions dominate.

A second group of regions with enhanced $\mathrm{NO}_{2}$ columns is linked to areas with intense biomass burning, mainly in Southern America, Africa and Indonesia. These signals are smaller than those observed over polluted regions and show a clear seasonality that can be matched to fire counts also observed from space. While some of the patterns repeat every year, e.g. in Africa, some depend on special conditions such as the El Nino and vary strongly in intensity from year to year. From the satellite maps it appears that outside the industrialised countries, biomass burning is the largest source of $\mathrm{NO}_{2}$ in the troposphere. 

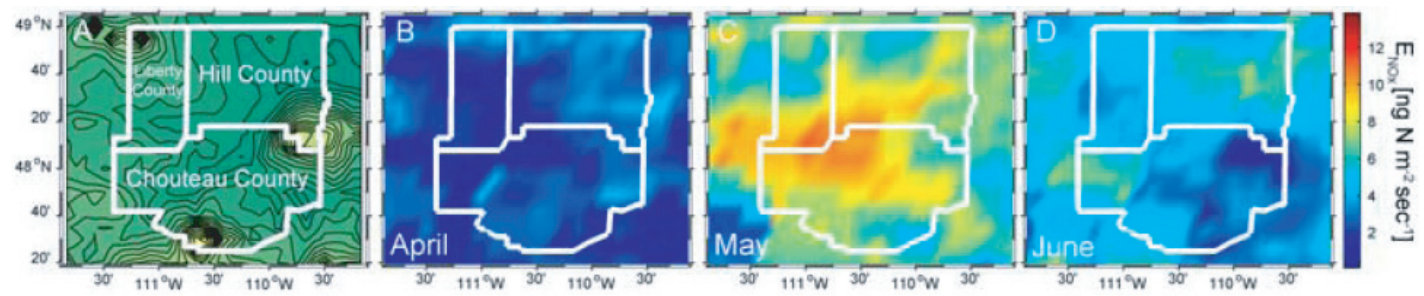

Fig. 3. Topographical map of North-Central Montana (A), an area with low population, few industrial $\mathrm{NO}_{x}$ sources but much agriculture. Figures $\mathrm{B}-\mathrm{D}$ show the NOx emissions as derived from $\mathrm{NO}_{2}$ measurements of the SCIAMACHY instrument [18]. Copyright 2005 American Geophysical Union.

Another interesting observation is the lack of strong $\mathrm{NO}_{2}$ signals in regions of known pollution export. For example, polluted air masses are often transported from the US towards Europe but there is no indication for this in the averaged satellite maps. This is explained by the short atmospheric life time of $\mathrm{NO}_{2}$ (few hours at the surface and days in the upper troposphere) and the shift of the $\mathrm{NO}$ to $\mathrm{NO}_{2}$ equilibrium towards $\mathrm{NO}$ in the upper parts of the troposphere where transport is most efficient. Thus, satellite $\mathrm{NO}_{2}$ measurements over source free regions can be used to determine the $\mathrm{NO}_{2}$ lifetime $[8,15]$ but only under favourable conditions, transport can be observed directly e.g. [16,17].

The short atmospheric lifetime of $\mathrm{NO}_{2}$ facilitates establishing a direct link between observed $\mathrm{NO}_{2}$ columns and $\mathrm{NO}_{x}$ emissions strengths as will be discussed in section 3.3. In particular in summer, transport can be neglected on the spatial scale of several degrees on which emissions are usually derived and high $\mathrm{NO}_{2}$ columns can be directly interpreted as indicative for large $\mathrm{NO}_{x}$ emissions. In many regions, several emission sources contribute to the signal observed and in particular over Europe, a pollution background of elevated values exists. However, in some areas the observed $\mathrm{NO}_{2}$ can directly be related to individual emission sources such as ships or power plants as will be discussed further below. For this type of applications the observation of the integrated tropospheric column is an advantage over in-situ measurements of mixing ratios on the ground which depend on the depth of the surface boundary layer.

\subsection{Process studies}

As satellite observations provide global data sets, they can be analysed from many different perspectives. Examples are the study of biomass burning events which release large amounts of $\mathrm{NO}_{x}$ and $\mathrm{CO}$ into the atmosphere (e.g. [19]), analysis of lightning events and their effects on $\mathrm{NO}_{2}$ levels ([20-22]) or the extraction of the weekly cycle of $\mathrm{NO}_{2}$ over industrialised regions which can be used to estimate anthropogenic emissions and also the $\mathrm{NO}_{2}$ atmospheric life time [23].

Another example of such a specific analysis is shown in figure 3, a study on $\mathrm{NO}_{2}$ levels over the rural area of North-Central Montana. In this part of the US, population is low and there are no large stationary $\mathrm{NO}_{x}$ sources. However, after fertiliser application to the large agricultural area, peaks of enhanced $\mathrm{NO}_{2}$ can be observed in the SCIAMACHY data, and these measurements have been used to constrain the parameters of a model describing microbial soil emissions of $\mathrm{NO}_{x}$ as a function of humidity, fertilisation and temperature [18]. Soil emissions of $\mathrm{NO}_{x}$ have also been observed in GOME measurements of $\mathrm{NO}_{2}$ over Africa where they are not linked to application of fertilisers [24].

\subsection{NOx emission studies}

As already mentioned above, the short lifetime of $\mathrm{NO}_{2}$ facilitates determining $\mathrm{NO}_{x}$ emissions from $\mathrm{NO}_{2}$ column observations. As proper emission estimates are relevant input for atmospheric modelling and also of political interest in the context of planning and evaluation of emission 

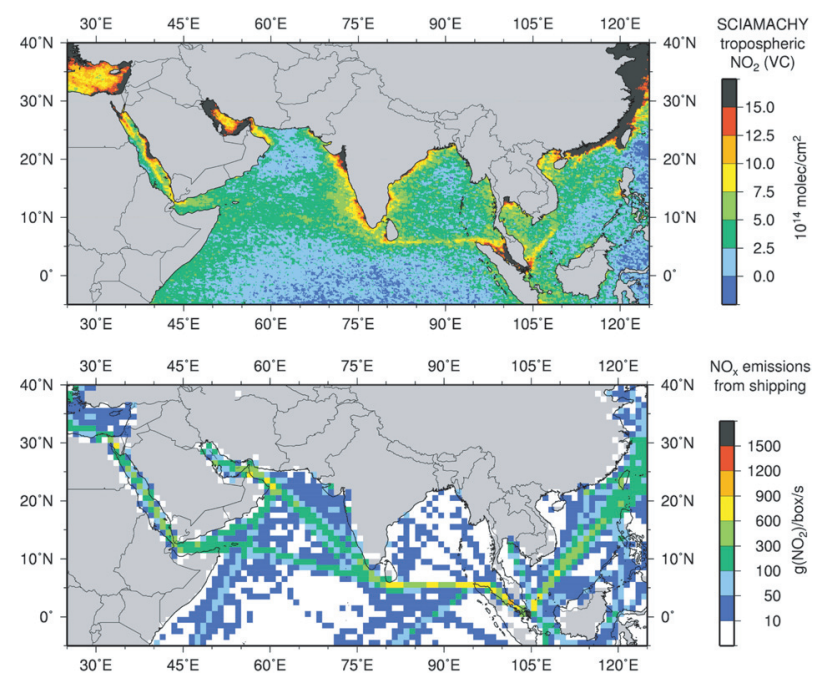

Fig. 4. $\mathrm{NO}_{2}$ columns derived from SCIAMACHY measurements between August 2002 and April 2004 (upper panel) and bottom up estimates of shipping emissions (lower panel) [27]. Copyright 2004 American Geophysical Union.

controls, this is one of the most relevant application fields for satellite data. Over the last years, a number of studies have been published using tropospheric $\mathrm{NO}_{2}$ columns derived from measurements of the GOME, SCIAMACHY, OMI, and GOME-2 instruments to derive information on anthropogenic $\mathrm{NO}_{x}$ emissions. These studies can be broadly divided into three different types: Those attempting global inversion of the data using 3d-CTM at low resolution (e.g. [25, 26]), those focusing on individual emission sources such as ships or power plants and those evaluating temporal changes in emissions. Some examples of the latter two will be discussed below.

\subsubsection{Shipping emissions}

With increasing globalisation, more and more goods are transported by ship between the US, Europe and Asia and further rapid growth of the transport volume as well as the number of ships is predicted for the coming years [28]. With increased shipping also the emissions of ships are expected to grow, in particular as emissions of ships in international waters are little regulated.

In most regions of the oceans, ship traffic density is low and the exhausts are quickly diluted to levels undetectable from space. Close to the shores and ports, shipping emissions are more concentrated but can not easily be separated from land based emissions which often are also large close to harbours. However, in some regions of the oceans, ships travel on well defined narrow tracks resulting in enhanced concentrations of $\mathrm{NO}_{x}$ far away from other sources which can be observed from space. An example is shown in figure 4. A thin line of enhanced $\mathrm{NO}_{2}$ can be tracked from the Mediterranean through the Red Sea to the southern tip of India, to Indonesia and then up towards China where it is lost. This pattern is in excellent agreement with that of the bottom-up inventory but shows more details on the exact position of the ship tracks. Comparison of the predicted emissions with those derived from the satellite data and estimates of the atmospheric lifetime of $\mathrm{NO}_{2}$ show agreement within the uncertainties.

Parts of the shipping tracks have also been observed in GOME data [29], and that study also evaluated the seasonal change in position and extension of the $\mathrm{NO}_{2}$ signal. Both are in agreement with seasonal wind patterns. A more recent study including also GOME-2 data showed good overall agreement but larger GOME-2 than SCIAMACHY than GOME columns which could be related to both, the diurnal cycle of $\mathrm{NO}_{2}$ linked to the different satellite overpass times and the increase in shipping emissions over the last decade [30]. 


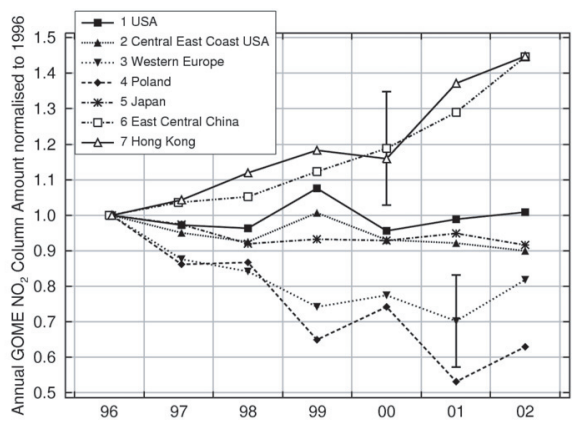

Fig. 5. Evolution of GOME based tropospheric $\mathrm{NO}_{2}$ columns relative to the reference year 1996 for selected regions. The error bars give an estimate of the combined random and systematic uncertainty of the derived column changes [31].

\subsubsection{Global changes in NOx emissions}

With the combined GOME and SCIAMACHY time series extending over more than a decade, evaluation of the data set for changes over this time period becomes interesting. Results of the analysis of GOME data from 1996 to 2002 are shown in figure 5 for some selected regions [31]. While $\mathrm{NO}_{2}$ levels over the US and Japan remained more or less unchanged, significant reductions were observed over Europe and a strong increase over China. The changes in $\mathrm{NO}_{2}$ columns were interpreted as changes in $\mathrm{NO}_{x}$ emissions assuming that both viewing conditions and atmospheric lifetime of $\mathrm{NO}_{2}$ were unchanged over time. A similar but extended analysis including also SCIAMACHY data yielded comparable results indicating the robustness of the conclusions $[32,33]$ and extending on other aspects of the data such as source assignment.

In particular the large increase over China was of interest as it appears to be linked to the rapid economic development in parts of the country which has led to increasing problems with air quality. However, bottom-up inventories indicated that after initial increase in emissions, $\mathrm{NO}_{x}$ levels should have stabilised after 1998 in contradiction to the satellite observations. Re-evaluation of the assumptions going into the bottom-up inventory revealed that significant changes in technology occurred which were not well represented in the initial data set, and an updated estimate is in much better agreement with the satellite data [34]. This is an excellent example on how satellite measurements can be used to identify deficiencies in current emission estimates and to evaluate global change.

More sophisticated inversions have also been applied to smaller geographical regions using a combination of GOME and SCIAMACHY data [35]. The resulting temporal trends in $\mathrm{NO}_{x}$ emissions on country level were compared to those resulting from EMAP bottom-up emissions and showed varying levels of agreement. This is taken as indication that some of the EMAP emission changes do not fully reflect the changes over the last decade, again highlighting the power of satellite measurements to monitor emission changes from space.

\subsubsection{Changes in NOx emissions from power plants}

With improving spatial resolution, satellite data can also be used to directly monitor the effects of emission regulations on tropospheric $\mathrm{NO}_{2}$ levels. An example is shown in figure 6 for the Eastern US, where $\mathrm{NO}_{2}$ columns retrieved from SCIAMACHY measurements in summer 2004 are compared to output from the WRF-chem model [36]. The model clearly over-predicts $\mathrm{NO}_{2}$ columns in the Ohio Valley region, an area with many coal fired power plants. This is in contrast to other parts of the domain where much better agreement is found and also to previous years, where satellite columns over the Ohio Valley were significantly larger. This discrepancy could be explained by $\mathrm{NO}_{x}$ emission reductions of power plants in summer required by legislation to reduce summer ozone levels. When a second model run using updated $\mathrm{NO}_{x}$ emissions from 

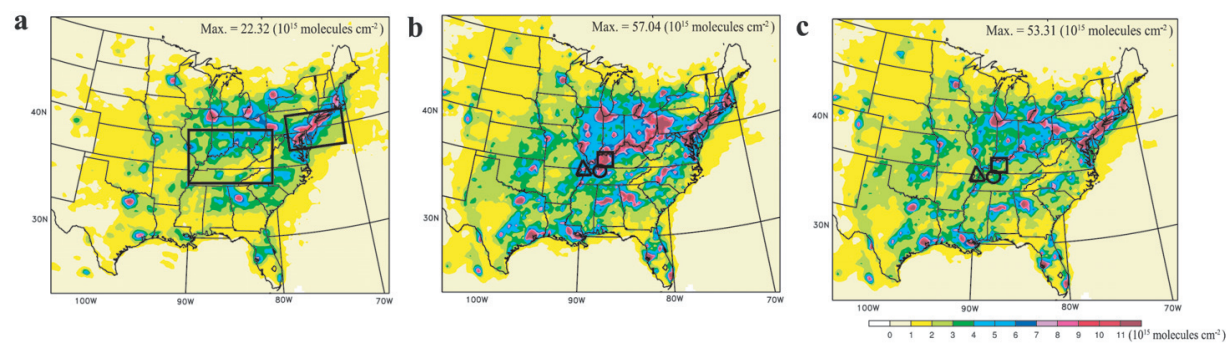

Fig. 6. Tropospheric $\mathrm{NO}_{2}$ columns above the Eastern US measured and modelled for June - August 2004. a) SCIAMACHY measurements, b) WRF-chem results using the base emissions, and c) WRFchem results using updated emissions [36]. Copyright 2006 American Geophysical Union.

power plants was compared to the satellite data, the differences were much reduced (see figure 6). While the emission reduction could also be directly monitored at the power plants using in-situ measurements, the satellite data observe the effect of the pollution control measures on regional air quality.

Analysis of the SCIAMACHY $\mathrm{NO}_{2}$ signal over a number of large and relatively isolated power plants in the US revealed large changes in signal for some of them that could be linked to periods of reduced operation, indicating that with a spatial resolution of $60 \times 30 \mathrm{~km}^{2}$ or better, emissions from individual large power plants can be monitored from space.

\section{Summary and outlook}

As illustrated by the examples given above, satellite measurements of tropospheric $\mathrm{NO}_{2}$ have already been successfully applied in many studies on atmospheric chemistry. They provide the global fields needed for validation of atmospheric models, they can be inverted to derive emission estimates from continental down to regional scales, they monitor atmospheric change over long time periods globally and can be used for better understanding of atmospheric processes.

In the future, exploitation of the full information content of the growing data base of satellite measurements will continue with similar studies. The work on emission estimates will be extended using the longer data sets created by combining measurements from different instruments. The higher spatial resolution of the new instruments will facilitate application of satellite data on regional scales which makes them more appropriate for process studies. Improvements in retrieval algorithms and the accuracy of the a priori data used will reduce uncertainties in current satellite data as will averaging over longer time periods. Integration of satellite $\mathrm{NO}_{2}$ products into data assimilation systems has the potential to improve the forecasting skills of such models and might become standard procedure for pollution prediction.

Satellite measurements of tropospheric $\mathrm{NO}_{2}$ will have a completely new quality when geostationary observations become available. These data can provide measurements of the diurnal cycle at good spatial resolution, albeit only over part of the globe. The combination of small ground pixels and repeated measurements will reduce problems with clouds and create a much more representative data set than current sensors. Plans for geostationary satellites with appropriate instrumentation are currently actively pursued in Europe, the US and Japan and could become reality in the next decade.

Parts of this work were funded by the University of Bremen and by the European Union through the ACCENT project.

\section{References}

1. S. Solomon, et al., J. Geophys. Res. Atmos. 104, 12047 (1999)

2. U. Platt, D. Perner, H.W. Pätz, J. Geophys. Res. Oceans Atmos. 84, 6329 (1979) 
3. J.F. Noxon, Science 189, 547 (1975)

4. S. Solomon, A.L. Schmeltekopf, R.W. Sanders, J. Geophys. Res. Atmos. 92, 8311 (1987)

5. R.V. Martin, et al., J. Geophys. Res. Atmos. 107, 4437 (2002)

6. A. Richter, J.P. Burrows, Adv. Space Res. 29, 1673 (2002)

7. K.F. Boersma, H.J. Eskes, E.J. Brinksma, J. Geophys. Res. Atmos. 109 (2004) doi: 10.1029/2003JD003962

8. C. Leue, et al., J. Geophys. Res. Atmos. 106, 5493 (2001)

9. E.J. Bucsela, et al., IEEE Trans. Geosci. Remote Sensing 44, 1245 (2006)

10. J.P. Burrows, et al., J. Atmos. Sci. 56, 175 (1999)

11. H. Bovensmann, et al., J. Atmos. Sci. 56, 127 (1999)

12. P.F. Levelt, et al., IEEE Trans. Geosci. Remote Sensing 44, 1093 (2006)

13. J. Callies, et al., ESA Bull. 102 (2000)

14. K.F. Boersma, et al., J. Geophys. Res. Atmos. 113 (2008)

15. T. Kunhikrishnan, et al., Geophys. Res. Lett. 31 (2004)

16. A. Stohl, et al., Atmos. Chem. Phys. 3, 969 (2003)

17. N. Spichtinger, et al., Geophys. Res. Lett. 28, 4579 (2001)

18. T.H. Bertram, et al., Geophys. Res. Lett. 32 (2005)

19. D.P. Edwards, et al., J. Geophys. Res. Atmos. 108 (2003)

20. S. Beirle, et al., Atmos. Chem. Phys. 6, 1075 (2006)

21. Y. Choi, et al., Geophys. Res. Lett. 32 (2005)

22. K.F. Boersma, et al., Atmos. Chem. Phys. 5, 2311 (2005)

23. S. Beirle, et al., Atmos. Chem. Phys. 3, 2225 (2003)

24. L. Jaegle, et al., J. Geophys. Res. Atmos. 109 (2004)

25. L. Jaegle, et al., Faraday Disc. 130, 407 (2005)

26. R.V. Martin, et al., J. Geophys. Res. Atmos. 108 (2003)

27. A. Richter, et al., Geophys. Res. Lett. 31 (2004)

28. V. Eyring, et al., Atmos. Chem. Phys. 7, 757 (2007)

29. S. Beirle, et al., Geophys. Res. Lett. 31 (2004)

30. K. Franke, et al., Atmos. Chem. Phys. Disc. 8, 15997 (2008)

31. A. Richter, et al., Nature 437, 129 (2005)

32. R.J. van der, et al., J. Geophys. Res. Atmos. 113 (2008)

33. R.J. van der, et al., J. Geophys. Res. Atmos. 111 (2006)

34. Q. Zhang, et al., J. Geophys. Res. Atmos. 112 (2007)

35. I.B. Konovalov, et al., Atmos. Chem. Phys. 8, 2623 (2008)

36. S.W. Kim, et al., Geophys. Res. Lett. 33 (2006) 